\title{
Effect of superabsorbent polymer admixtures on hygric and thermal properties of cement mortar
}

\author{
Jan For̆t ${ }^{1}$, Petr Hotěk ${ }^{1}$, Martin Mildner ${ }^{1}$, Jitka Krejsová ${ }^{1}$ and Robert Černý ${ }^{1, *}$ \\ ${ }^{1}$ Department of Materials Engineering and Chemistry, Faculty of Civil Engineering, Czech Technical University in Prague, Thákurova 7, \\ Prague 6, 160 00, Czech Republic
}

\begin{abstract}
Materials known as superabsorbent polymers (SAP) or hydrogels are currently used in quite a few applications, ranging from diapers or napkins to nutrient carriers and soil conditioners. The great ability of SAPs to absorb and hold a significant amount of water can be utilized well also in the construction sector. For instance, SAPs can serve as effective admixtures for mitigation of autogenous shrinkage of highperformance concrete, frost protection, or cracks sealing. In this paper, basic physical, hygric and thermal properties of cement mortars containing superabsorbent polymer admixtures are analyzed. Basic physical characteristics are measured using the water vacuum saturation method and helium pycnometry. Moisture diffusivity is determined by utilizing the results of water sorptivity measurements, water vapor diffusion permeability is measured by the cup method. Sorption isotherms are determined by the desiccator method in the range of relative humidity of $11 \%-96 \%$. Thermal conductivity and specific heat capacity are measured by pulse method. Experimental results show a very significant dependence of all hygric and thermal parameters on the SAP dosage in the mix.
\end{abstract}

\section{Introduction}

Concrete, as the most used man-made building material, stands out by high compressive strength, long-term durability, resistance to various aggressive environments, relatively low cost and abundance. Therefore, it is not surprising that annual worldwide concrete production exceeded 53 billion tons in 2014 and is further increased as a result of population growth [1]. On the other hand, despite all benefits, this building material is unfortunately quasi-brittle and highly vulnerable against microcracking [2]. In order to increase the functional properties of conventional concrete, modern concrete mixtures are modified by various admixtures to reduce the water/cement ratio (w/c) and thus improve the mechanical strength [3]. The application of low w/c is unfortunately accompanied by insufficient cement hydration which may induce selfdesiccation and autogenous shrinkage [4]. The consequent crack formation endangers the durability of concrete elements, decreases their resistance to aggressive chemical pollutants which may easily penetrate the structure and cause damage to steel reinforcement [5]. At later ages, cracks grow wider and may induce even total collapse of the damaged construction. In light of these facts, the inspection, precautions, maintenance, and repair of cracks take place in order to increase the service life of damaged construction. Notwithstanding, these actions are often very difficult and expensive [6].
The above-mentioned problems can be mitigated by utilizing the self-healing ability of concrete [7]. The principle of self-healing is well known; the cracks may be healed themselves when exposed to water. However, this works only for very narrow cracks and depends on many other factors, such as the amount of unhydrated cement particles, hydraulic pressure and temperature [2]. In order to improve this phenomenon, several approaches have been studied. Besides the application of lightweight aggregates, bacteria, tubes or capsules with healing agents, the internal curing by using superabsorbent polymers as smart adaptable materials was found as highly beneficial for mitigation of autogenous shrinkage and promotion of self-healing itself [8]. The relevant benefits compared to other admixtures can be characterized as follows: even a small amount of SAP can substantially improve the internal curing, enhance a resistance to freeze-thaw attack, promote the strength gain at later ages, and stimulate the self-healing [9].

Despite those benefits, SAP incorporation has a fundamental impact on functional properties [10]. In particular, the influence of SAP on the pore structure formation in cement-based materials is crucial. This phenomenon is related to a rapid swelling of SAP particles when exposed to batch water, the formation of hydrogel structure with increased viscosity affects the workability of the fresh mixture [11]. To maintain the desired level of concrete fresh mixture workability, extra water must be added. Unfortunately, according to Ma et al. [12], the needs for additional water dosage are usually

Corresponding author: cernyr@fsv.cvut.cz 
negatively reflected by resulting mechanical strength. Therefore, the amount of extra water needs to be precisely determined to minimize associated negative consequences [13]. The secondary effect consists in a formation of voids as a reaction to consequent desiccation and shrinkage of SAP particles during the curing period. Furthermore, these changes are related to the amount of applied SAPs, their particle size distribution and chemical composition $[14,15]$. Lin et al. [16] highlighted that apart from the mixture design and adjustment of rheologic properties, the effect of applied SAPs on resulting material properties needs to be studied since all denoted effects correlate with significant changes in the concrete microstructure.

This study is aimed at the investigation of changes in basic physical, hygric and thermal properties of cement mortars containing SAP admixtures. The effect of increasing SAP dosage on designed cement mortar mixtures is considered. Understanding the influence of different SAP contents on the fundamental material properties belongs to critical concerns of SAP application in cementitious materials.

\section{Experimental}

\subsection{Studied materials}

Studied cement mortars were composed of the following components: Portland cement CEM I 42.5 R, quartz sand with a maximum particle size of $4 \mathrm{~mm}$, water, superplasticizer and acrylic-based SAP (Evonic). According to data provided by the SAP manufacturer, the powder density of Cabloc CT is $590 \mathrm{~kg} / \mathrm{m}^{3}$. SAP used for this study is a low-crosslinking sodium acrylate which is able to absorb about $80 \mathrm{~g}$ of distilled water per 1 gram.

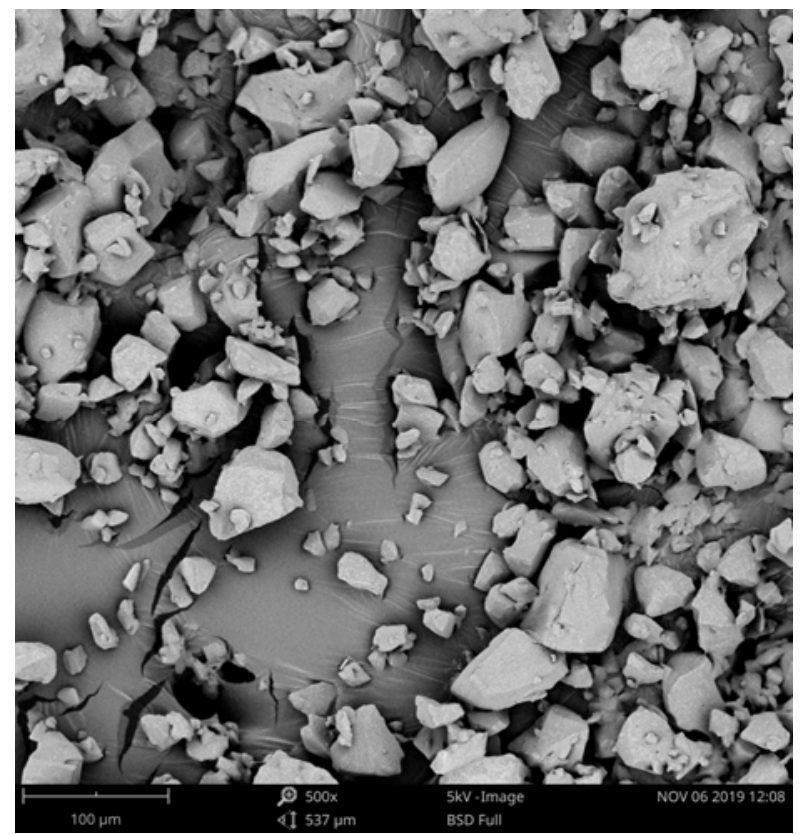

Fig. 1. SEM image of SAP Cabloc CT.
The scanning electron microscope (SEM) image of SAP particles, as obtained using a Phenom XL (ThermoScientific) device having a magnification range from 80 to 100 000, is shown in Fig. 1 .

The particle size distribution of SAP was determined by laser diffraction analyzer Bettersize S3 Plus (Bettersize Instruments) with a measuring range from $0.01 \mu \mathrm{m}$ to $3,500 \mu \mathrm{m}$. The results are presented in Figure 2. As one can see, the particle size distribution curve revealed a maximum around $290 \mu \mathrm{m}$.

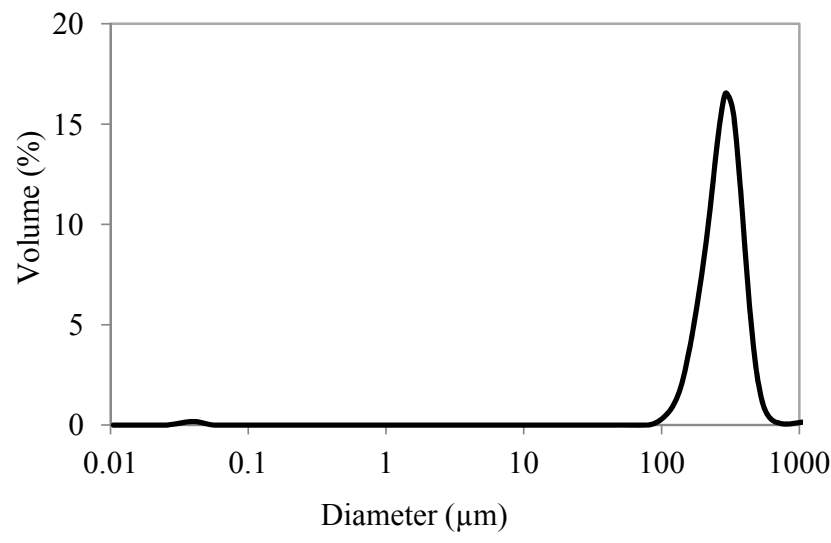

Fig. 2. Particle size distribution of SAP.

The amount of additional water needed to maintain the same workability of mixtures was determined on the basis of European Standard EN 12350-5 and w/c was adjusted accordingly. The composition of studied mixtures given in Table 1 was adopted from [17]

Table 1. Composition of studied mixtures.

\begin{tabular}{|l|c|c|c|c|c|}
\hline Mixture & $\begin{array}{c}\text { Cement } \\
\left(\mathrm{kg} / \mathrm{m}^{3}\right)\end{array}$ & $\begin{array}{c}\text { Fine } \\
\text { aggregate } \\
\left(\mathrm{kg} / \mathrm{m}^{3}\right)\end{array}$ & $\begin{array}{c}\mathrm{SP} \\
\left(\mathrm{kg} / \mathrm{m}^{3}\right)\end{array}$ & $\begin{array}{c}\text { SAP } \\
\text { dosage } \\
\left(\mathrm{kg} / \mathrm{m}^{3}\right)\end{array}$ & w/c \\
\hline CR_P0 & 350 & 1650 & 0.5 & 0 & 0.30 \\
\hline CS0.25 & 350 & 1650 & 0.5 & 1.375 & 0.34 \\
\hline CS0.5 & 350 & 1650 & 0.5 & 2.750 & 0.36 \\
\hline CS0.75 & 350 & 1650 & 0.5 & 4.125 & 0.4 \\
\hline CS1 & 350 & 1650 & 0.5 & 5.500 & 0.43 \\
\hline
\end{tabular}

\subsection{Experimental methods}

\subsubsection{Basic material properties}

The bulk density, matrix density and total open porosity of designed mixtures in the hardened state were determined. The bulk density was given by weighing of the dried samples and determination of their volume by using a digital caliper. For measurement of the matrix density a helium pycnometry device Pycnomatic ATC (Thermo Scientific) was used. The total open porosity was calculated on the basis of the knowledge of bulk and matrix density. All results were calculated from five independent measurements. 


\subsubsection{Mechanical properties}

The compressive and bending strength were determined using a hydraulic testing device Servoplus Evolution (Matest) having a stiff loading frame with capacity up to $6000 \mathrm{kN}$. Both compressive and bending strengths were measured after 28 days of water curing. Three prismatic samples having a size of $40 \mathrm{~mm} \times 40 \mathrm{~mm} \times 160 \mathrm{~mm}$ were used for bending strength measurement and the fragments of specimens leftover after the bending strength test were used for compressive strength determination.

\subsubsection{Hygric properties}

The liquid water transport properties were determined by using the common sorptivity concept [18]. Five cubic samples having a side of $50 \mathrm{~mm}$ were insulated on lateral sides to ensure 1-D transport. The measurement was based on a periodical weighing of samples by employing automatic balances. Sorptivity $S\left(\mathrm{~m} / \mathrm{s}^{-1 / 2}\right)$ is defined as

$$
I=S \cdot t^{1 / 2}
$$

where $I(\mathrm{~m})$ is the cumulative absorption of water and $t$ (s) the time of absorption. This simplification is based on the general expression for the cumulative mass of water in terms of the square-root-of-time rule that is commonly employed in the diffusion theory, which is obtained by dividing the original equation

$$
i=A \cdot t^{1 / 2}
$$

by the density of water, $\rho_{\mathrm{w}}$.

In Eq. $2, i\left(\mathrm{~kg} / \mathrm{m}^{2}\right)$ is the cumulative mass of water and $A\left(\mathrm{~kg} / \mathrm{m}^{2} \mathrm{~s}^{1 / 2}\right)$ the water absorption coefficient related to the sorptivity according to Eq. 3 ,

$$
A=S \cdot \rho_{w}
$$

Consequently, the apparent moisture diffusivity $\kappa_{\text {app }}\left(\mathrm{m}^{2} / \mathrm{s}\right)$ was calculated according to

$$
\kappa_{\text {app }} \approx\left(\frac{A}{w_{\text {sat }}}\right)^{2}
$$

where $w_{\text {sat }}\left(\mathrm{kg} / \mathrm{m}^{3}\right)$ is the saturated moisture content of the analyzed material.

Water vapor transmission properties were measured using the cup method under isothermal conditions. Five samples with circular cross-section having a diameter of $110 \mathrm{~mm}$, whereas the sample thickness was $30 \mathrm{~mm}$ were used. The cup containing silica gel and having the analyzed specimen sealed on its top by technical plasticine was placed in a controlled climatic chamber, where the constant relative humidity of $50 \%$ and constant temperature of $21^{\circ} \mathrm{C}$ was maintained. Consequently, it was weighed periodically until the steady-state values of mass gain per unit time were obtained [19].

The water vapor diffusion permeability was calculated according to

$$
\delta=\frac{\Delta m \cdot d}{S \cdot \tau \cdot \Delta P_{p}}
$$

where $\Delta m(\mathrm{~kg})$ is the mass of water vapor diffused through the sample, $d(\mathrm{~m})$ the sample thickness, $S\left(\mathrm{~m}^{2}\right)$ the specimen surface, $\tau$ (s) the period of time corresponding to the transport of mass $\Delta m$ of water vapor, and $\Delta P p(\mathrm{~Pa})$ is the difference between partial water vapor pressure in the air under and above specific specimen surface.

By using $\delta$ values calculated from Eq. 5, the water vapor diffusion coefficient is given as

$$
D=\delta \frac{R \cdot T}{M}
$$

where $T(\mathrm{~K})$ is temperature, $R(8.314 \mathrm{~J} / \mathrm{K} \mathrm{mol})$ the universal gas constant, and $M(18.02 \mathrm{~g} / \mathrm{mol})$ the molar mass of water vapor.

Afterward, the water vapor diffusion resistance factor $\mu(-)$, widely used for the description of building materials was calculated as

$$
\mu=\frac{D_{a}}{D}
$$

where $D_{a}\left(\mathrm{~m}^{2} / \mathrm{s}\right)$ is the water vapor diffusion coefficient in the air.

A dynamic vapor sorption device DVS Advantage (Surface Measurement Systems) was employed for the determination of sorption and desorption isotherms at 21 ${ }^{\circ} \mathrm{C}$. The device measures the uptake and loss of water vapor gravimetrically, using highly precise balances with a resolution of $1.0 \mu \mathrm{g}$. Such a high resolution is obtained by hanging samples on the end of a beam where the position of the beam is measured by an optical sensor. The desired vapor pressure is generated by mixing the saturated and dry carrier gas streams, using electronic mass flow controllers. The measuring humidity range is $0-98 \%$ with the declared accuracy $\pm 0.5 \%$. The DVS Advantage instrument is designed to provide isothermal measurements in the temperature range from 5 to $60{ }^{\circ} \mathrm{C}$ with the accuracy $\pm 0.1^{\circ} \mathrm{C}$. The temperature is controlled within the measurement by a unit using Pt100 temperature sensors.

Before the particular measurement, samples were firstly dried in a vacuum oven at $80^{\circ} \mathrm{C}$ and then kept in desiccators during the cooling. After drying, samples were inserted into the climatic chamber of the DVS Advantage and exposed to the $0,20,40,60,80$, and 95 $\mathrm{RH} \%$ levels. Each step in RH during the DVS measurement was done either when a stable mass was achieved with mass change less than $0.00004 \% / \mathrm{min}$ or a maximum time interval of $400 \mathrm{~min}$ was reached. Because reaching the sample mass equilibrium at high $\mathrm{RH}$ was difficult, the maximum time interval of sample exposure to $80 \%$ was increased to $3000 \mathrm{~min}$, and at $98 \%$ to $6000 \mathrm{~min}$ [19].

\subsubsection{Thermal properties}

Thermal conductivity and specific heat capacity were determined by the pulse method, using an Isomet 2104 device. Three $70 \mathrm{~mm} \times 70 \mathrm{~mm} \times 70 \mathrm{~mm}$ specimens were 
used in the experiments. The measurement process was based on an analysis of the temperature response of analyzed material to heat flow pulses. The range of measurement is from $0.015 \mathrm{~W} /(\mathrm{mK})$ to $6 \mathrm{~W} /(\mathrm{mK})[20]$. The thermal conductivity measurement accuracy given by the producer is $5 \%$ of reading $+0.001 \mathrm{~W} /(\mathrm{mK})$. The experiments were performed under constant laboratory conditions at $21^{\circ} \mathrm{C}$ and $30 \% \mathrm{RH}$.

\section{Results and discussion}

\subsection{Basic material properties}

The total open porosity, bulk and matrix density are shown in Table 2. As one can see, the application of SAP admixture affected the above-mentioned quantities. While the matrix density was influenced only in a minor way and the variations could be assigned to the measurement uncertainties, more obvious differences were found for the bulk density. With the increasing amount of applied SAP, the bulk density decreased compared to results obtained for the reference mixture. Accordingly, the total open porosity increased from an initial 15.41 to $23.83 \%$.

Table 2. Basic material properties of studied mixtures.

\begin{tabular}{|l|c|c|c|}
\hline Mixture & $\begin{array}{c}\text { Bulk } \\
\text { density } \\
\left(\mathrm{kg} / \mathrm{m}^{3}\right)\end{array}$ & $\begin{array}{c}\text { Matrix } \\
\text { density } \\
\left(\mathrm{kg} / \mathrm{m}^{3}\right)\end{array}$ & $\begin{array}{c}\text { Total open porosity } \\
(\%)\end{array}$ \\
\hline CR_P0 & 2190 & 2589 & 15.41 \\
\hline CS0.25 & 2156 & 2576 & 16.30 \\
\hline CS0.5 & 2087 & 2579 & 19.08 \\
\hline CS0.75 & 2023 & 2566 & 21.16 \\
\hline CS1 & 1953 & 2564 & 23.83 \\
\hline
\end{tabular}

The observed changes can be partially explained by the higher amount of used batch water during the preparation of the modified mixtures. They can also be considered as the first important information for the understanding of the relationship between material properties and the amount of used SAP.

\subsection{Mechanical properties}

Both bending and compressive strength after 28 days of curing decreased for all modified mixtures (Fig. 3). The compressive strength dropped gradually in the line with the increased amount of used SAP up to $11 \%$ for CS1 mixture. On the other hand, the bending strength was influenced by a lesser extent. The observed changes in strength can be attributed to the increased swelling capability of SAP particles and thus voids formation.

Considering the current advances in the design of cement mortar mixtures with self-healing admixtures, a noticeable development in strength can be expected at a later age.

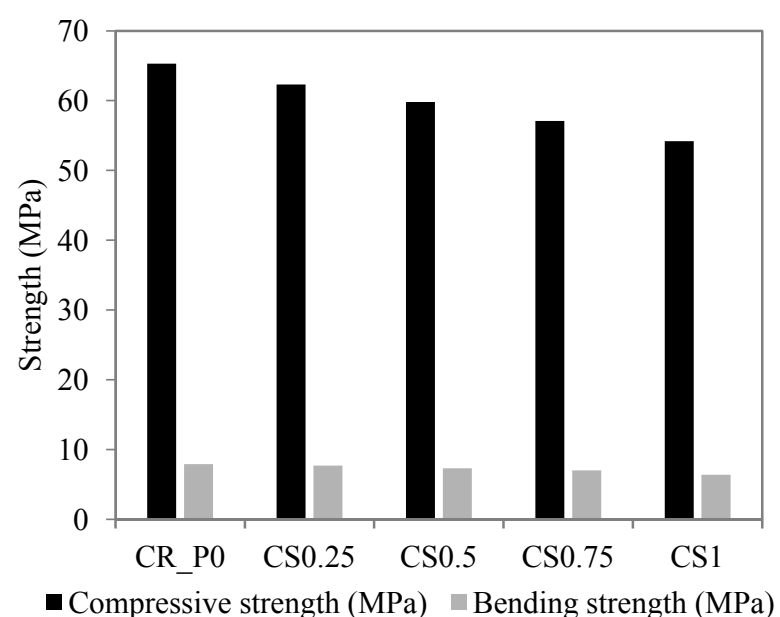

Fig. 3. Mechanical properties of studied materials.

\subsection{Hygric properties}

The liquid water transport properties of studied mixtures are described in Table 3. The obtained results corresponded with the changes in pore volume which noticeably affected the water transport capability. Specifically, the water absorption coefficient increased from an initial $0.009 \mathrm{~kg} / \mathrm{m}^{2} \mathrm{~s}^{1 / 2}$ for the reference mixture to $0.032 \mathrm{~kg} / \mathrm{m}^{2} \mathrm{~s}^{1 / 2}$ for the mixture modified by $1 \mathrm{wt} . \%$ of SAP. The apparent moisture diffusivity followed a similar trend. On the other hand, it should be noted that a further swelling of SAPs may create an impermeable layer if SAP particles will be fully saturated.

Table 3. Liquid water transport properties of studied materials.

\begin{tabular}{|l|c|c|}
\hline Mixture & $\begin{array}{c}\text { Water absorption } \\
\text { coefficient }\left(\mathrm{kg} / \mathrm{m}^{2} \mathrm{~s}^{1 / 2}\right)\end{array}$ & $\begin{array}{c}\text { Apparent moisture } \\
\text { diffusivity }\left(\mathrm{m}^{2} / \mathrm{s}\right)\end{array}$ \\
\hline CR_P0 & 0.009 & $4.39 \mathrm{E}-09$ \\
\hline CS0.25 & 0.012 & $6.44 \mathrm{E}-09$ \\
\hline CS0.5 & 0.019 & $7.74 \mathrm{E}-09$ \\
\hline CS0.75 & 0.023 & $9.34 \mathrm{E}-09$ \\
\hline CS1 & 0.032 & $2.28 \mathrm{E}-08$ \\
\hline
\end{tabular}

The changes in water vapor diffusion parameters of studied mixtures (Table 4) were similar to liquid water transport properties. Particularly, the water vapor resistance factor was reduced in line with the increased amount of applied SAP. This finding complied with the observed increased open porosity and higher water absorption coefficient.

Table 4. Water vapor transport properties of studied materials.

\begin{tabular}{|l|c|c|}
\hline Mixture & $\begin{array}{c}\text { Water vapor diffusion } \\
\text { permeability }(\mathrm{s})\end{array}$ & $\begin{array}{c}\text { Water vapor diffusion } \\
\text { resistance factor }(-)\end{array}$ \\
\hline CR_P0 & $2.03 \mathrm{E}-12$ & 83.1 \\
\hline CS0.25 & $2.26 \mathrm{E}-12$ & 74.8 \\
\hline CS0.5 & $2.54 \mathrm{E}-12$ & 70.3 \\
\hline CS0.75 & $2.79 \mathrm{E}-12$ & 63.7 \\
\hline CS1 & $2.98 \mathrm{E}-12$ & 57.9 \\
\hline
\end{tabular}


The water vapor storage capability of all studied materials plotted in Fig. 4 showed similar results. The reference mixture revealed the lowest sorption of water vapor while for all mixtures modified by SAPs a slightly increased sorption was observed, according to a higher volume of pores. Additionally, the mixtures with SAP exhibited increased hysteresis compared to the reference samples which can be explained by the water retention capability of used SAPs.

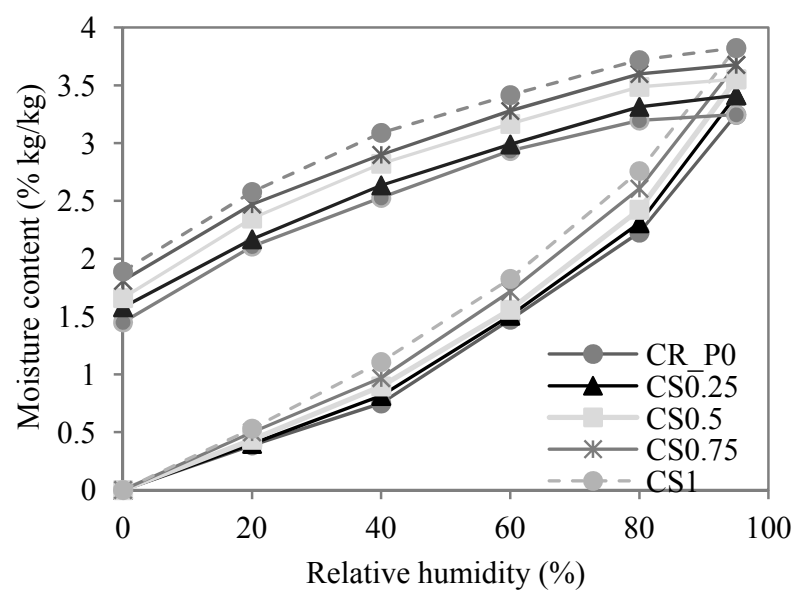

Fig. 4. Sorption isotherms.

\subsection{Thermal properties}

The thermal conductivity and specific heat capacity in dry state are presented in Table 5. Apparently, the addition of SAP improved the thermal insulation properties but slightly reduced the specific heat capacity. The drop in thermal conductivity reached $22 \%$ while the specific heat capacity was lowered only by $6 \%$. The noticed difference in thermal conductivity was caused by the higher total open porosity of samples modified by SAP and by the low thermal conductivity of dry SAP particles $(0.69 \mathrm{~W} / \mathrm{mK})$ [21]. The decrease of specific heat capacity could not be explained in a convincing way as it was within the range of measurement uncertainty.

Table 5. Water vapor transport properties of studied materials.

\begin{tabular}{|l|c|c|}
\hline Mixture & $\begin{array}{c}\text { Thermal conductivity } \\
(\mathrm{W} /(\mathrm{mK}))\end{array}$ & $\begin{array}{c}\text { Specific heat } \\
\text { capacity }(\mathrm{J} /(\mathrm{kg} \mathrm{K}))\end{array}$ \\
\hline CR_P0 & 1.86 & 776 \\
\hline CS0.25 & 1.75 & 769 \\
\hline CS0.5 & 1.69 & 765 \\
\hline CS0.75 & 1.61 & 764 \\
\hline CS1 & 1.46 & 732 \\
\hline
\end{tabular}

The influence of increased moisture content on thermal conductivity is shown in Fig. 5. As it could be expected, the increased water content substantially increased the thermal conductivity; in the watersaturated state, the thermal conductivity reached almost two times higher values than in the dry state for all studied mixtures. This negative phenomenon can cause worsening of thermal performance of structures built from studied cement mortars. Specific heat capacity increased with increasing moisture content in a similar way to thermal conductivity, which was due to the very high specific heat capacity of water (Fig. 6).

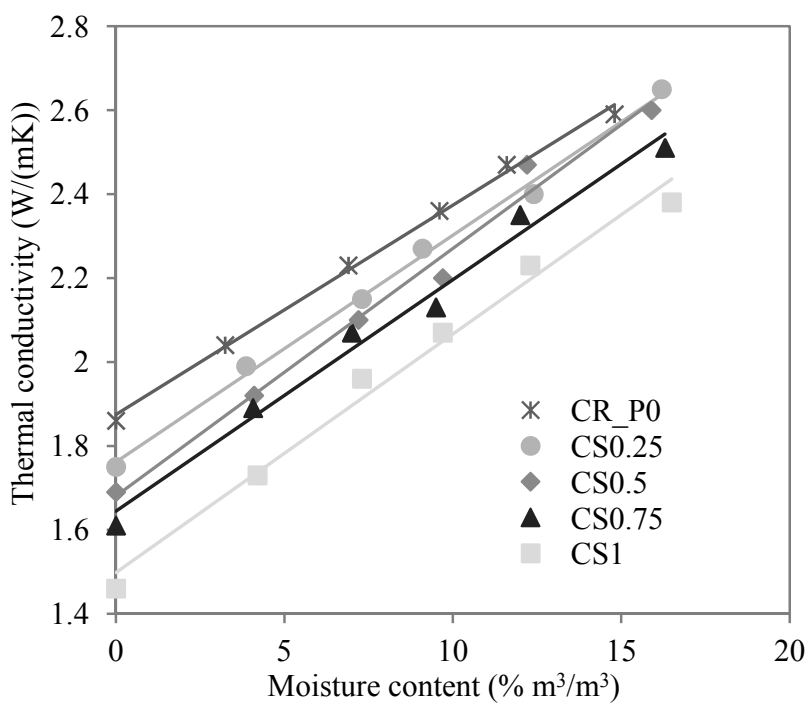

Fig. 5. Moisture dependent thermal conductivity.

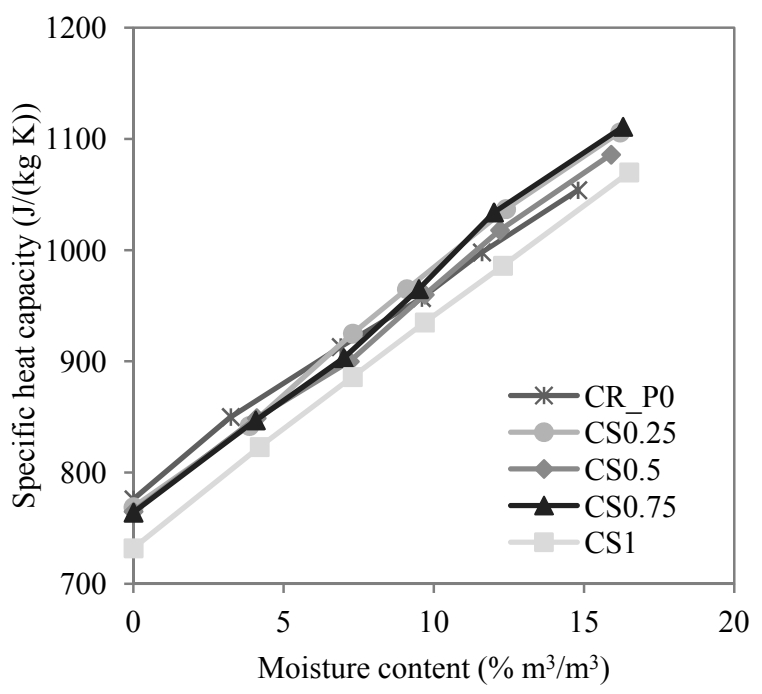

Fig. 6. Moisture dependent specific heat capacity.

\section{Conclusions}

The experimental analysis of cement mortars with SAP admixture was presented. The reference mixture was modified by $0.25,0.5,0.75$, and $1 \mathrm{wt} . \%$ of SAP in order to describe the impact of applied admixture. The obtained results showed that even small portions of incorporated SAP admixture can induce substantial changes in functional properties. The usage of SAP led to an increase in total open porosity as a result of the worsening of rheologic properties and swelling capability of SAP particles. The main consequences were the decrease of compressive strength, bending strength and thermal conductivity and the increase of 
water absorption coefficient, water vapor diffusion permeability and water vapor sorption. Considering the obtained results, mixtures up to $0.75 \mathrm{wt} \%$ provide sufficient strength parameters together with substantial improvements in hygric properties.

The authors gratefully acknowledge the financial support received from the Czech Science Foundation, under project No. 19-14789S.

\section{References}

1. B. Lothenbach, K. Scrivener, R. D. Hooton, Cem. Conc. Res. 41, 1244 (2011)

2. K. Van Tittelboom, N. De Belie, Materials 6, 2182 (2013)

3. O. M. Jensen, P. F. Hansen, Cem. Conc. Res. 31, 647 (2001)

4. S. Zhutovsky, K. Kovler, Cem. Conc. Res. 20, 40 (2012)

5. D. Snoeck, L. Pel, N. De Belie, Constr. Build. Mater. 223, 244 (2019)

6. J. M. Medina, I. F. S. del Bosque, M. Frias, M. I. S. de Rojas, C. Medina, Constr. Build. Mater. 225, 429 (2019)

7. H. Y. Wang, W. T. Kuo, C. C. Lin, C. Po-Yo, Constr. Build. Mater. 41, 532 (2013)

8. C. Schrofl, D. Snoeck, V. Mechtcherine, Mater. Struct. 50, (2017)

9. M. T. Hasholt, O. M. Jensen, K. Kovler, S. Zhutovsky, Constr. Build. Mater. 31, 226 (2012)

10. J. T. Dang, J. Zhao, Z. H. Du, Polymers-Basel 9, 17 (2017)

11. S. H. Kang, S. G. Hong, J. Moon, Cem. Conc. Res. 97, 73 (2017)

12. X. W. Ma, Q. Yuan, J. H. Liu, C. J. Shi, Constr. Build. Mater. 195, 66 (2019)

13. S. H. Kang, S. G. Hong, J. Moon, Constr. Build. Mater. 172, 29 (2018)

14. H. X. D. Lee, H. S. Wong, N. R. Buenfeld, Cem. Conc. Res. 79, 194 (2016)

15. B. B. Sun, H. Wu, W. M. Song, Z. Li, J. Yu, Constr. Build. Mater. 204, 440 (2019)

16. R. F. Lin, L. F. Pang, J. Cer. Proces. Res. 20, 231 (2019)

17. E. Vejmelková, D. Koňáková, T. Kulovaná, M. Keppert, M. Žumár, P. Rovnaníková, Z. Keršner, M. Sedlmajer, R. Černý, Cem. Concr. Comp. 55, 259 (2015)

18. C. Hall, Mag. Concr. Res. 37, 78 (1989)

19. Z. Pavlík, J. Fořt, M. Pavlíková, J. Pokorný, A. Trník, R. Černý, Energ. Build. 126, 113 (2016)

20. J. Fořt, Z. Pavlík, K. Durana, R. Černý, Mater. SciMedzg. 21, 455 (2015)

21. V. Kočí, J. Kočí, J. Maděra, Z. Pavlík, X. L. Gu, W. P. Zhang, R. Černý, J. Build. Phys. 41, 497 (2018) 